\title{
Highly efficient and irreversible removal of cadmium through the formation of a solid solution
}

\author{
Chen Wang ${ }^{\mathrm{a}, \mathrm{d}}$, Hui Yin ${ }^{\mathrm{e}}$, Lei Bi ${ }^{\mathrm{a}, *}$, Jing Su ${ }^{\mathrm{a}, \mathrm{d}}$, Meiyi Zhang ${ }^{\mathrm{a}}$, Tao Lyu ${ }^{\mathrm{b}, \mathrm{c}}$, Mick Cooper ${ }^{\mathrm{b}, \mathrm{c}}$, \\ Gang $\operatorname{Pan}^{\mathrm{a}, \mathrm{b}, \mathrm{c}, \mathrm{f}, *}$
}

${ }^{a}$ Key Laboratory of Environmental Nanotechnology and Health Effects, Research Center for Eco-Environmental Sciences, Chinese Academy of Sciences, 18 Shuangqing Road, Haidian District, Beijing, 100085, PR China

${ }^{\mathrm{b}}$ School of Animal, Rural, and Environmental Sciences, Nottingham Trent University, Brackenhurst Campus, NG25 OQF, UK

${ }^{\mathrm{c}}$ Centre of Integrated Water-Energy-Food Studies (iWEF), School of Animal, Rural, and Environmental Sciences, Nottingham Trent University, Brackenhurst Campus, NG25 OQF, UK

${ }^{\mathrm{d}}$ University of Chinese Academy of Sciences, Beijing, 100049, PR China

${ }^{\mathrm{e}}$ Key Laboratory of Arable Land Conservation (Middle and Lower Reaches of Yangtze River), Ministry of Agriculture and Rural Affairs, College of Resources and

Environment, Huazhong Agricultural University, Wuhan, 430070, PR China

${ }^{\mathrm{f}}$ Beijing Advanced Science and Innovation Center of CAS, Chinese Academy of Sciences, Beijing, PR China

\section{G R A P H I C A L A B S T R A C T}

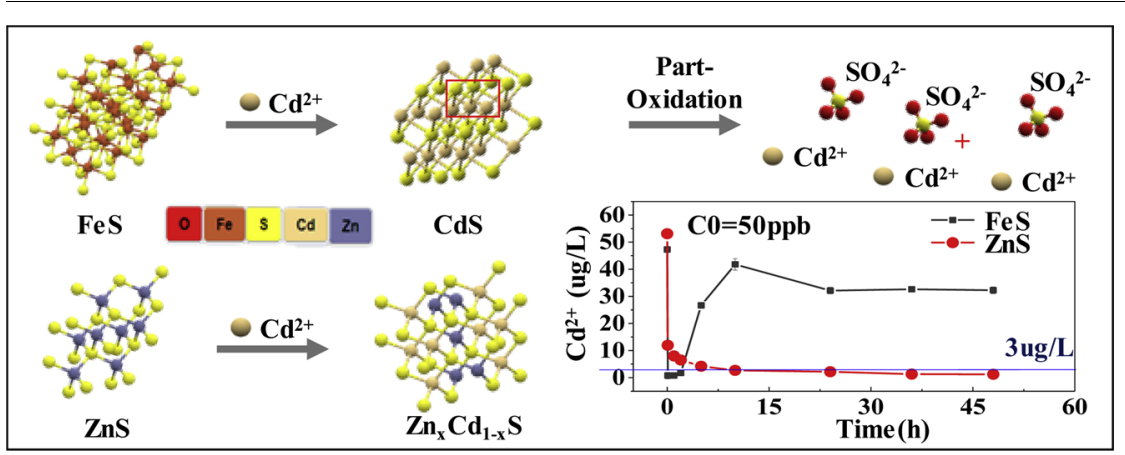

\section{A R T I C L E I N F O}

\section{Editor: R Teresa}

Keywords:

Metal sulfides

Environmental remediation

Heavy metal

Solid solution

\begin{abstract}
A B S T R A C T
Sulfur-containing materials are very attractive for the efficient decontamination of some heavy metals. However, the effective and irreversible removal of $\mathrm{Cd}^{2+}$, coupled with a high uptake efficiency, remains a great challenge due to the relatively low bond dissociation energy of CdS. Herein, we propose a new strategy to overcome this challenge, by the incorporation of $\mathrm{Cd}^{2+}$ into a stable $\mathrm{Zn}_{\mathrm{x}} \mathrm{Cd}_{1-\mathrm{x}} \mathrm{S}$ solid solution, rather than into CdS. This can be realised through the adsorption of $\mathrm{Cd}^{2+}$ by $\mathrm{ZnS}$ nanoparticles, which have exhibited a $\mathrm{Cd}^{2+}$ uptake capacity of approximate $400 \mathrm{mg} \mathrm{g}^{-1}$. Through this adsorption mechanism, the $\mathrm{Cd}^{2+}$ concentration in a contaminated solution could effectively be reduced from $50 \mathrm{ppb}$ to $<3 \mathrm{ppb}$, a WHO limit acceptable for drinking water. In addition, ZnS continued to exhibit this noteworthy uptake capacity even in the presence of $\mathrm{Cu}^{2+}, \mathrm{Pb}^{2+}$, and $\mathrm{Hg}^{2+}$. $\mathrm{ZnS}$ displayed high chemical stability. Particles aged in air for 3 months still retained a $>80 \%$ uptake capacity for $\mathrm{Cd}^{2+}$, compared with only $9 \%$ uptake capacity for similarly-aged FeS particles. This work reveals a new mechanism for $\mathrm{Cd}^{2+}$ removal with $\mathrm{ZnS}$ and establishes a valuable starting point for further studies into the formation of solid solutions for hazardous heavy metal removal applications.
\end{abstract}

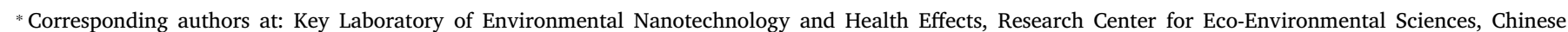
Academy of Sciences, 18 Shuangqing Road, Haidian District, Beijing, 100085, PR China.

E-mail addresses: leibi@rcees.ac.cn (L. Bi), gpan@rcees.ac.cn (G. Pan). 


\section{Introduction}

While cadmium (Cd) is a widespread and essential element as a component of electric batteries, pigments, coatings, electroplating solutions etc., it is also considered as one of the most harmful heavy metals, due to bioaccumulation in the food chain and its toxicity to humans and other species (Clemens et al., 2013). $\mathrm{Cd}^{2+}$ accumulation has been reported at levels up to $578 \mathrm{mg} / \mathrm{kg}$ in Hunan-grown rice from China (Qu et al., 2016), where the World Health Organization's (WHO) maximum guideline concentration is $1 \mathrm{mg} / \mathrm{kg}$. The WHO limit for $\mathrm{Cd}^{2+}$ concentration acceptable for drinking water is $3 \mathrm{ppb}$ (Water and Organization, 2006). In addition, the Environmental Bulletin of China, in 2016, reported that the average excess of cadmium in the marine fishery waters was $3.4 \% . \mathrm{Cd}^{2+}$ contamination in both soil and water environments has thus become a serious threat to food safety and public health and, therefore, effective removal of $\mathrm{Cd}$ from the environment has become an urgent problem that needs to be solved.

Sulfur-containing materials are very attractive for efficient decontamination of heavy metals, e.g. $\mathrm{Hg}^{2+}, \mathrm{Pb}^{2+}, \mathrm{Cu}^{2+}$, from contaminated water, owing to the strong affinity between these metals and $\mathrm{S}$ (Zhang et al., 2016; Ma et al., 2016a; Su et al., 2019). The formation of CdS is commonly regarded as the main mechanism for $\mathrm{Cd}^{2+}$ removal by sulfur-containing materials. Iron sulfide $(\mathrm{FeS})$ is the most used sulfurcontaining material in the treatment of groundwater and soil contaminated with heavy metals, due to its ubiquitous presence, strong affinity, facile synthesis and being less affected by interfering ions (Xiong et al., 2009). Sulfide precipitation and ion exchange with $\mathrm{Fe}^{2+}$ have been considered as the two possible mechanisms for removing heavy metals by formation of CdS (Gong et al., 2016). However, FeS is not thermodynamically stable and may suffer from corrosion in water. FeS can also react with water to generate hydrogen sulfide, leading to a loss of $\mathrm{S}^{2-}$, and eventually decreasing the removal capacity for heavy metals (Mansurov et al., 2018). In addition, $\mathrm{Fe}^{2+}$ can be oxidized to $\mathrm{Fe}_{2} \mathrm{O}_{3}$, which would significantly inhibit any ion exchange functionality for heavy metal removal. Although various techniques have been explored in order to enhance the uptake capacity of FeS for heavy metals $\left(\mathrm{Hg}^{2+}, \mathrm{Cu}^{2+}, \mathrm{Pb}^{2+}\right.$, and $\mathrm{Cr}^{5+}$ ) (Kim et al., 2011; Su et al., 2015; Wu et al., 2017; Zhang et al., 2019a), it is still demanding to significantly increase removal rates of $\mathrm{Cd}^{2+}$. This may be caused by the relatively low bond dissociation energy (BDE) of CdS, when compared to other metal sulfides (Table 1) (Luo, 2007). The low BDE value could allow $\mathrm{CdS}$ to be easily oxidized to soluble $\mathrm{CdSO}_{4}$, thus leading to the reversible release of $\mathrm{Cd}^{2+}$ (Pujalte et al., 2015; Gao et al., 2015). Therefore, the development of novel strategies for the effective and irreversible removal of $\mathrm{Cd}^{2+}$ remains a great challenge (Ma et al., 2016b).

The application of $\mathrm{FeS}$ for $\mathrm{Cd}^{2+}$ removal has hitherto relied on the reaction between $\mathrm{Cd}^{2+}$ and $\mathrm{S}^{2-}$ to form CdS by precipitation. However, the chemical instability of FeS and the high re-release rate of $\mathrm{Cd}^{2+}$ from the thus-formed CdS could significantly reduce the expected efficiency of $\mathrm{Cd}^{2+}$ removal. To the contrary, $\mathrm{Zn}^{2+}$ is relatively stable and is not easily oxidized, because zinc is not, strictly, a member of the 'transition' elements, owing to its filled $d$ shells (Lennartson, 2014; MartinGonzalez et al., 2006). Additionally, $\mathrm{Zn}^{2+}$ has similar ionic radius to $\mathrm{Cd}^{2+}$ and could thus inhibit $\mathrm{Cd}^{2+}$ adsorption (Gao et al., 2018). As a typical solid solution semiconductor (Zhang et al., 2019b), ZnCdS is much more stable than CdS (Wang et al., 2018a; Bailey et al., 2017; Zeuthen et al., 2019). ZnS may have a different removal mechanism from $\mathrm{FeS}$ and thus be able to exhibit superior performance for the removal of $\mathrm{Cd}^{2+}$. To date, there have been several studies on the removal of heavy metals using ZnS (Fang et al., 2018; Sahoo et al., 2014), although only limited research has been conducted to evaluate the effectiveness of $\mathrm{ZnS}$ for $\mathrm{Cd}^{2+}$ removal. Moreover, none have systematically investigated the underlying mechanisms for $\mathrm{Cd}^{2+}$ removal.

Herein, we propose a new strategy to address the aforementioned challenges for $\mathrm{Cd}^{2+}$ removal, by employing $\mathrm{ZnS}$ as a nano-capture agent. It is hypothesised that removal of $\mathrm{Cd}^{2+}$ is through the formation of a solid solution, $\mathrm{Zn}_{\mathrm{x}} \mathrm{Cd}_{1-\mathrm{x}} \mathrm{S}$. This material exhibits better thermodynamic stability than CdS, which would reduce the re-release of $\mathrm{Cd}^{2+}$ and provide excellent resistance to interfering ions. In an attempt to explain the exceptional affinity of $\mathrm{ZnS}$ for $\mathrm{Cd}^{2+}$ capture, the mechanism for the formation of solid solution ZnCdS is investigated systematically by Rietveld structure refinement, high-resolution transmission electron microscopy (HR-TEM) and Raman analyses. This work provides a new perspective on the capture of $\mathrm{Cd}^{2+}$ from water, and highlights the use of solid solutions as promising applications for the remediation of $\mathrm{Cd}^{2+}$ contaminated environments.

\section{Materials and methods}

\subsection{Synthesis of sulfide nanoparticles}

FeS and ZnS nanoparticles were synthesized using pre-established methods (Xiong et al., 2009; Wu et al., 2017). Briefly, $\mathrm{N}_{2}$-purged deionized (DI) water was firstly prepared by bubbling $\mathrm{N}_{2}$ (>99.9\%) into DI water for $30 \mathrm{~min}$, in order to remove dissolved oxygen. This $\mathrm{N}_{2^{-}}$ purged DI water was further used throughout the synthesis process. Previously-prepared $0.043 \mathrm{M} \mathrm{FeSO}_{4}$ solution $(10 \mathrm{~mL})$ was added to the $\mathrm{N}_{2}$-purged DI water $\left(52.5 \mathrm{~mL}\right.$ ) under continued $\mathrm{N}_{2}$ purging and constant stirring, after which pre-prepared $0.085 \mathrm{M} \mathrm{Na}_{2} \mathrm{~S}$ solution $(5 \mathrm{~mL})$ was then added dropwise, forming a suspension of FeS nanoparticles. The suspension was then centrifuged, the supernatant discarded and the nanoparticles further washed, separated and vacuum dried for $24 \mathrm{~h}$ under $60^{\circ} \mathrm{C}$. $\mathrm{ZnS}$ nanoparticles were also prepared by the same process, although employing $\mathrm{ZnSO}_{4}$ as the source of cations.

Cadmium nitrate $\left(\mathrm{CdN}_{2} \mathrm{O}_{6} \cdot 4 \mathrm{H}_{2} \mathrm{O}\right)$ was dissolved in DI water with $5 \%$ vol nitric acid to prevent hydrolysis. This stock solution was then appropriately diluted to obtain solutions with target $\mathrm{Cd}^{2+}$ concentrations ( $50 \mathrm{ppb} \& 600 \mathrm{ppm}$ ) for use in the adsorption tests. All chemicals used in the study were of analytical grade and purchased from Sinopharm Group Co., Ltd, Beijing.

\subsection{Batch experiments}

The first batch experiment was performed in order to evaluate the $\mathrm{Cd}^{2+}$ removal abilities of FeS and $\mathrm{ZnS}$ from two different contaminated waters. The initial concentrations of $\mathrm{Cd}^{2+}$ were set at $50 \mathrm{ppb}$ and $60 \mathrm{ppm}$ in order to simulate polluted natural water (Pandey et al., 2019) and mining industrial waste (Addala and Belattar, 2017), respectively. Experiments were performed with $20 \mathrm{mg}$ of the adsorbents and $200 \mathrm{~mL}$ of $\mathrm{Cd}^{2+}$ solution in $500 \mathrm{~mL}$ Erlenmeyer flasks under continuous shaking $(120 \mathrm{rpm})$ at $25^{\circ} \mathrm{C}$. No prior $\mathrm{pH}$ adjustment was performed for all of the experiments, because of the relatively stable $\mathrm{pH}$ (Fig. S1). For the experiment with the initial $\mathrm{Cd}^{2+}$ concentration of $50 \mathrm{ppb}, 5 \mathrm{~mL}$ water samples were taken for $\mathrm{Cd}^{2+}$ quantification at 0 , $0.083,1,2,5,10,24,36$, and at the end of the experiment, at $48 \mathrm{~h}$. During the experiment conducted with the initial $\mathrm{Cd}^{2+}$ concentration of $60 \mathrm{ppm}$, water samples $(5 \mathrm{~mL})$ were taken for analysis at $0,0.083,1,2$,

Table 1

Bond dissociation energies (BDEs) (Luo, 2007) of S-X Bonds.

\begin{tabular}{lll}
\hline The broken bonds & \multicolumn{2}{l}{ BDEs } \\
\cline { 2 - 3 } & $\mathrm{kcal} / \mathrm{mol}$ & $\mathrm{kJ} / \mathrm{mol}$ \\
\hline $\mathrm{Ni}-\mathrm{S}$ & $85 \pm 5$ & $356 \pm 21$ \\
$\mathrm{Co}-\mathrm{S}$ & 79 & 331 \\
$\mathrm{Cu}-\mathrm{S}$ & $65.6 \pm 3.5$ & $274.5 \pm 14.6$ \\
$\mathrm{~Pb}-\mathrm{S}$ & $55 \pm 15$ & $230 \pm 63$ \\
$\mathrm{Hg}-\mathrm{S}$ & $51.9 \pm 5.3$ & $217.3 \pm 22.2$ \\
$\mathrm{Ag}-\mathrm{S}$ & $51.8 \pm 3.5$ & $216.7 \pm 14.6$ \\
$\mathrm{Cd}-\mathrm{S}$ & $49.8 \pm 5$ & $208.5 \pm 20.9$ \\
\hline
\end{tabular}


$5,10,24,33,48,54,72,84$, and $96 \mathrm{~h}$. The experiment ended after $96 \mathrm{~h}$. In order to understand the $\mathrm{Cd}^{2+}$ removal mechanisms, residual nanoparticles (ca. $20 \mathrm{mg}$ ) were taken at the conclusion of these batch experiments and dried in a vacuum oven $\left(60^{\circ} \mathrm{C}, 48 \mathrm{~h}\right)$ for surface morphology analysis.

After $\mathrm{Cd}^{2+}$ adsorption by FeS, it is expected that the released Fe(II) be oxidized to $\mathrm{Fe}(\mathrm{III})$ in the presence of $\mathrm{O}_{2}\left(\mathrm{t}_{1 / 2}<\right.$ hours at $\left.\mathrm{pH} 6-7\right)$ is this $t_{1 / 2}$ (halflife) or $t=1-2$ hours or $t=1 / 2 h$, by which process superoxide and peroxide anions can also be generated. Thereafter, CdS is hypothesised to be oxidized by the superoxide radical $\left(\cdot \mathrm{O}_{2}{ }^{-}\right)$, hydroxyl radicals $(\cdot \mathrm{OH})$, singlet oxygen $\left({ }^{1} \mathrm{O}_{2}\right)$ and/or $\mathrm{Fe}(\mathrm{III})$. In order to understand the possible pathway of CdS oxidation, four inhibitors $(1.5 \mathrm{mM}$ carotene, $1.5 \mathrm{mM}$ p-benzoquinone, $450 \mathrm{mM}$ tert-butanol and $12 \mathrm{mM}$ sodium fluoride) were added separately into each solution treated with FeS following the batch experiment with an initial $\mathrm{Cd}^{2+}$ concentration of $50 \mathrm{ppm}$. Water samples $(5 \mathrm{~mL})$ were taken for analysis at $0,0.083,5$, $10,24,33,48,72$ and $96 \mathrm{~h}$.

To understand the theoretical maximum Cd adsorption capacities of materials, adsorption isotherm experiments were conducted in $50 \mathrm{~mL}$ centrifuge tubes with $3 \mathrm{mg}$ of the materials (FeS or $\mathrm{ZnS}$ ) and $30 \mathrm{~mL}$ of $\mathrm{Cd}^{2+}$ solution (10-600 ppm). In total, 12 centrifuge tubes were prepared for each material, which were constantly agitated for $48 \mathrm{~h}$ at $25^{\circ} \mathrm{C}$. Adsorption data were fitted to Freundlich and Langmuir isotherm models (Table S1).

In addition to the evaluation of $\mathrm{Cd}^{2+}$ adsorption capacity, three separate batch experiments were conducted in order to investigate possible effects on $\mathrm{Cd}^{2+}$ removal from interference of co-existing metal ions, from $\mathrm{Cd}^{2+}$ re-release, and from nanoparticle chemical stability. i) Mixed solutions, each containing six cations $\left(\mathrm{Cd}^{2+}, \mathrm{Cu}^{2+}, \mathrm{Pb}^{2+}, \mathrm{Hg}^{2+}\right.$, $\mathrm{Ca}^{2+}$ and $\mathrm{Mg}^{2+}$ ), were prepared and the initial $\mathrm{pH}$ adjusted to 3. Initial $\mathrm{Cd}^{2+}, \mathrm{Cu}^{2+}, \mathrm{Pb}^{2+}, \mathrm{Hg}^{2+}$ concentrations were set at 1 and $10 \mathrm{ppm}$ and for each of these solutions, the concentrations of $\mathrm{Ca}^{2+}$ and $\mathrm{Mg}^{2+}$ were prepared at 60 and $600 \mathrm{ppm}$, respectively. Tests were carried out with $200 \mathrm{mg}$ of each material ( $\mathrm{FeS}$ or $\mathrm{ZnS}$ ) added to $200 \mathrm{~mL}$ solution in $500 \mathrm{~mL}$ Erlenmeyer flasks, under continuous shaking for $48 \mathrm{~h}$ at $25^{\circ} \mathrm{C}$. ii) In order to observe re-release of $\mathrm{Cd}^{2+}, 200 \mathrm{mg}$ of each material (FeS or $\mathrm{ZnS}$ ) was added to $200 \mathrm{~mL}$ of $\mathrm{Cd}^{2+}$ solution ( $500 \mathrm{ppm}$ ) in a $500 \mathrm{~mL}$ Erlenmeyer flask under continuous shaking for $48 \mathrm{~h}$ at $25^{\circ} \mathrm{C}$. The FeS and $\mathrm{ZnS}$ nanoparticles $(200 \mathrm{mg}$ ), after the reaction with $500 \mathrm{ppm}$ of $\mathrm{Cd}^{2+}$, were then further continuously shaken for $24 \mathrm{~h}$ at $25^{\circ} \mathrm{C}$, with $200 \mathrm{~mL}$ DI water in a $500 \mathrm{~mL}$ Erlenmeyer flask. iii) Comparison of the $\mathrm{Cd}^{2+}$ removal capacities of freshly-synthesized and of aged nanoparticles was also conducted in this study. The aged particles were obtained by storing fresh materials in ambient air for three months. Tests were then carried out with $3 \mathrm{mg}$ of each material and $30 \mathrm{~mL}$ of $\mathrm{Cd}^{2+}$ solution $(60 \mathrm{ppm})$ under continuous shaking for $48 \mathrm{~h}$ at $25^{\circ} \mathrm{C}$. At the end of the experiment, $5 \mathrm{~mL}$ aliquots were taken from each flask in order to perform $\mathrm{Cd}^{2+}$ concentration analyses. All batch experiments were conducted in triplicate under ambient conditions without further oxygenation or deoxygenation processes applied.

\subsection{General analysis methods}

Inductively-Coupled Plasma Optical Emission Spectrometry (ICPOES) and Inductively-Coupled Plasma Mass Spectrometry (ICP-MS) analyses were performed with a Perkin Elmer Optima 8300 (Massachusetts, USA) and an Agilent 7500A (California, USA), respectively, in order to determine the concentrations of cations and total sulfur (TS). $\mathrm{SO}_{4}{ }^{2-}$ was analyzed spectrophotometrically (SmartChem200, AMS Alliance, Italy). The main form of sulfur was hydrogen sulfide $\left(\mathrm{H}_{2} \mathrm{~S}\right)$ and sulfate $\left(\mathrm{SO}_{4}{ }^{2-}\right)$ in solution when $\mathrm{pH}$ was at 5-7 (Zhang et al., 2017a). Thus, the concentration of $\mathrm{H}_{2} \mathrm{~S}$ could be calculated by subtracting $\mathrm{SO}_{4}{ }^{2-}$ from total sulfur. For sample preparation, the liquid was filtered through a Millipore Membrane Filter (MilliporeSigma, Massachusetts, USA) with an average pore diameter of $0.22 \mu \mathrm{m}$. Nitric acid was added until $1 \%$ acid concentration in the sample was reached.

BET surface areas were determined by measuring nitrogen $\left(\mathrm{N}_{2}\right)$ adsorption/desorption isotherms at $-196{ }^{\circ} \mathrm{C}$ on an ASAP 2020 analyser (Micromeritics Instrument Corp., USA). An X-ray diffractometer (X'Pert ${ }^{3}$ Powder, PANalytical, Netherlands), operated at a tube voltage of $40 \mathrm{kV}$ and a current of $40 \mathrm{~mA}$ with $1.2 \mathrm{~s}$ counting time per $0.02^{\circ} 2 \theta$ step, and a micro confocal Raman Spectrometer (LabRAM HR Evolution, HORIBA, France) were utilized to analyze the crystal structures and elemental compositions of the nanomaterials.

The Raman spectra of the sulfides, before and after reaction, were
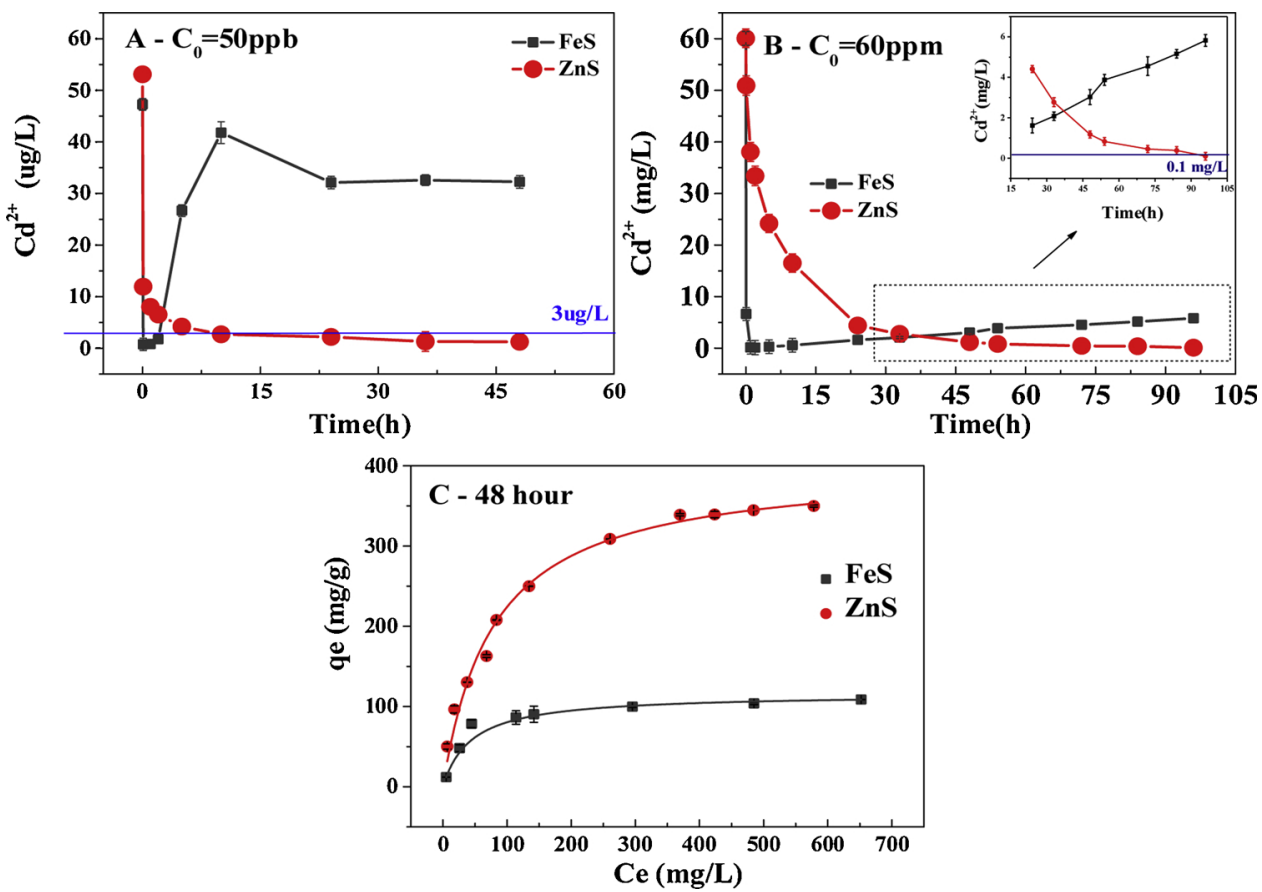

Fig. 1. $\mathrm{Cd}^{2+}$ removal by FeS and $\mathrm{ZnS}$ with time under different initial $\mathrm{Cd}^{2+}$ concentrations: (A) $50 \mathrm{ppb}$ and (B) $60 \mathrm{ppm}$. Sample dosage is $0.1 \mathrm{~g} \mathrm{~L}^{-1}$ and $1 \mathrm{~g} \mathrm{~L}$ respectively. Each solution had an initial pH of 6. (C) $48 \mathrm{~h}$ adsorption isotherms of $\mathrm{Cd}^{2+}$ on FeS and $\mathrm{ZnS}$. 
recorded using a He-Ne laser $(\lambda=532 \mathrm{~nm})$ with a monochromatic filter at room temperature, over the wavenumber range of $50 \mathrm{~cm}^{-1}$ to $2500 \mathrm{~cm}^{-1}$. Scanning Electron Microscopy (SEM) and High-Resolution Transmission Electron Microscopy (HR-TEM) images of the nanoparticles were obtained with an S-3000 N (Hitachi, Japan) at $10.0 \mathrm{kV}$ and a JEM-2100 (JEOL, Japan) equipped with an Energy-Dispersive Xray Spectrometer (EDS), respectively.

\section{Results and discussion}

\subsection{Performance of $\mathrm{Cd}^{2+}$ removal}

Adsorption tests were conducted to evaluate the $\mathrm{Cd}^{2+}$ removal ability of $\mathrm{ZnS}$, compared with FeS, from two different simulated $\mathrm{Cd}^{2+}$ contaminated waters. The initial concentration levels of $\mathrm{Cd}^{2+}$ were $50 \mathrm{ppb}$ and $60 \mathrm{ppm}$ to simulate polluted natural water (Pandey et al., 2019) and mining effluent (Addala and Belattar, 2017), respectively. The WHO limit for $\mathrm{Cd}^{2+}$ concentration in drinking water is $3 \mathrm{ppb}$ (Water and Organization, 2006) and a limit of $100 \mathrm{ppb}$ is set for industrial discharge (GB13456-2012) (Zhang et al., 2017b). It can be seen from Fig. $1 \mathrm{~A}$ and B that only ZnS achieved a sufficient $\mathrm{Cd}^{2+}$ removal that the final purified water attained regulatory compliance. Although the FeS treatment reached the maximum $\mathrm{Cd}^{2+}$ removal efficiency in the first hour, and met the WHO guidelines, the concentration of $\mathrm{Cd}^{2+}$ then gradually increased and had far surpassed the regulatory standard by the end of the experiment.

The maximum adsorption capacities of $\mathrm{FeS}$ and $\mathrm{ZnS}$ for $48 \mathrm{~h}$ were determined by study of the adsorption isotherms (Fig. 1C). The Langmuir isotherm model could better simulate the adsorption data than the Freundlich model (Table S1) and the corresponding correlation coefficients of the two adsorbents were above 0.99 (Table S2). ZnS showed the highest $\mathrm{Cd}^{2+}$ adsorption capacity $\left(401 \mathrm{mg} \mathrm{g}^{-1}\right.$ ), which is $\sim 3.5$ times higher than that $\left(116 \mathrm{mg} \mathrm{g}^{-1}\right)$ achieved by FeS. Existing sulfurfunctionalized substances from literature have been summarised along with their relevant $\mathrm{Cd}^{2+}$ adsorption capacities (Table 2), which further highlight the excellent $\mathrm{Cd}^{2+}$ removal performance of $\mathrm{ZnS}$. FeS exhibited rapid $\mathrm{Cd}^{2+}$ adsorption kinetics within a wide range of $\mathrm{Cd}^{2+}$ concentrations ( $50 \mathrm{ppb}$ and $60 \mathrm{ppm}$ ), which is likely to be appropriate for such industrial wastewater treatment applications. It is noted that the FeS materials would require replacement within $c a .1 .5 \mathrm{~h}$, in order to avoid re-release of $\mathrm{Cd}^{2+}$. $\mathrm{ZnS}$ requires a relatively long reaction equilibrium time but has an efficient and stable removal effect, suggesting that this material could be applied to longer-term environmental restoration projects, such as abandoned lakes, and derelict mining sites. Taking into account the relatively low cost of $\mathrm{ZnS}\left(0.09 \$ \mathrm{~kg}^{-1} \mathrm{Cd}\right.$ removed), compared with other treatment technologies (1.4-950 \$ $\mathrm{kg}^{-1} \mathrm{Cd}$ removed) (Adeleye et al., 2016) (Table S3), this material might further be developed for the remediation of numerous heavy metal cations and perhaps merit more use in the future. For real-world applications, permeable reactive barriers (PRB) and fixed beds have been widely employed for intercepting contaminants, with various reactive materials being used as the medium (Fu et al., 2014). Therefore, these systems, coupled with ZnS as the adsorption medium, may become a promising strategy for the effective remediation of $\mathrm{Cd}^{2+}$, and which require further investigation.

\subsection{Effect of Co-existing cations and stability studies}

The sulfide nanomaterials were dispersed into the mixed metal cation solutions in order to test their removal efficiencies. As shown in Fig. 2A, under a low initial Cd concentration (1 ppm), other metal ions present having little effect on cadmium removal for both metal sulfides. $\mathrm{ZnS}$ and $\mathrm{FeS}$ both achieved around $99 \%$ removal for $\mathrm{Cd}^{2+}, \mathrm{Cu}^{2+}, \mathrm{Pb}^{2+}$ and $\mathrm{Hg}^{2+}$ even in the environment where $\mathrm{Ca}^{2+}$ and $\mathrm{Mg}^{2+}$ were 60 times the concentration of other heavy metal ions. Both materials exhibited low removal capacities $(<10 \%)$ for $\mathrm{Ca}^{2+}$ and $\mathrm{Mg}^{2+}$. When the initial $\mathrm{Cd}^{2+}$ concentration was $10 \mathrm{ppm}$ (Fig. 2B), ZnS still achieved a high $\mathrm{Cd}^{2+}$ removal efficiency ( $>99 \%$ ) without interference by other metal cations. However, removal abilities by $\mathrm{FeS}$ for $\mathrm{Cd}^{2+}$ showed a clear decrease to around $45 \%$, the other metal cations present significantly inhibiting the removal rate. The continued low removal efficiencies for $\mathrm{Ca}^{2+}$ and $\mathrm{Mg}^{2+}$ may be caused by higher $\mathrm{K}_{\mathrm{sp}}$ values for $\mathrm{CaS}$ and MgS than that for CdS (Fang et al., 2018). Therefore, $\mathrm{Ca}^{2+}$ and $\mathrm{Mg}^{2+}$, as the common interfering ions in natural waters, appear to have little influence on the efficiencies of the sulfide nanomaterials for heavy metal removal. The synthesised $\mathrm{ZnS}$ nanoparticles exhibited more than a $99 \% \mathrm{Cd}^{2+}$ removal efficiency, even in the presence of various heavy metals at differing concentrations.

The low re-release rate of pollutants and high chemical stability are essential for practical applications in engineered remediation. Thus, we studied the re-release of $\mathrm{Cd}^{2+}$ from FeS and $\mathrm{ZnS}$ nanoparticles after reaction and their long-term stability when stored in air. After reaction, FeS exhibited a higher re-release rate of $\mathrm{Cd}^{2+}$, the concentration of $\mathrm{Cd}^{2+}$ reaching $8 \mathrm{mg} \mathrm{L}^{-1}$ after shaking in ultrapure water for $24 \mathrm{~h}$ (Fig. 2C). After treatment with $\mathrm{ZnS}$ nanoparticles, there was almost no re-release of $\mathrm{Cd}^{2+}$. Fig. 2D illustrates the removal efficiency of $\mathrm{Cd}^{2+}$ by aged metal sulfides, stored in air for three months. Compared with freshly-made sulfide nanoparticles, the aged $\mathrm{ZnS}$ still achieved $>80 \%$ removal efficiency of $\mathrm{Cd}^{2+}$, but only $9 \%$ efficiency was attained by the aged FeS. These results further illustrate that $\mathrm{ZnS}$ could be an efficient and reliable material for the removal of $\mathrm{Cd}^{2+}$.

\subsection{Metal cation release}

The formation of CdS precipitation by the consumption of hydrogen sulfide $\left(\mathrm{H}_{2} \mathrm{~S}\right)$ is one important mechanism for the removal of $\mathrm{Cd}^{2+}$ by sulfides (Gong et al., 2016). Therefore, it is necessary to observe the amount of $\mathrm{H}_{2} \mathrm{~S}$ released from the metal cations in order to investigate whether or not this is the mechanism responsible for the effects observed in this study. There was no $\mathrm{H}_{2} \mathrm{~S}$ release, both in DI water and $\mathrm{Cd}^{2+}$ solution, under ZnS treatment (Fig. S2), and thus it can be concluded that formation of CdS precipitated with $\mathrm{H}_{2} \mathrm{~S}$ is not the main

Table 2

$\mathrm{Cd}^{2+}$ adsorption capacities of selected sulfur-functionalized materials.

\begin{tabular}{|c|c|c|}
\hline Sulfur functionalized substances & $\mathrm{q}_{\mathrm{m}}^{\mathrm{a}}\left(\mathrm{mg} \mathrm{g}^{-1}\right)$ & Reference \\
\hline FeS & 116 & This study \\
\hline ZnS & 401 & This study \\
\hline Thiol-functionalized activated carbon (S-AC) & 130 & (Tang et al., 2018) \\
\hline Sulfide-modified nanoscale zerovalent iron & 150 & (Lv et al., 2018) \\
\hline S-ligand tethered cellulose nanofibers & 92 & (Abu-Danso et al., 2018) \\
\hline Sulfur functionalized graphene oxide Nanosheets with $\mathrm{TiO}_{2}$ coating & 384 & (Pirveysian and Ghiaci, 2018) \\
\hline Mercapto-modified graphene oxide nanosheets & 36 & (Sitko et al., 2015) \\
\hline Nitrogen and sulfur co-doped graphene-based aerogel & 197 & (Kong et al., 2018) \\
\hline Sulfur-functionalized rice husk & 137 & (Qu et al., 2018) \\
\hline Bacterially produced $\mathrm{FeS}$ & 109 & (Watson et al., 1995) \\
\hline
\end{tabular}

a The maximum adsorption capacities $\left(\mathrm{q}_{\mathrm{m}}\right)$ were fitted by Langmuir or Freundlich isotherm models. 

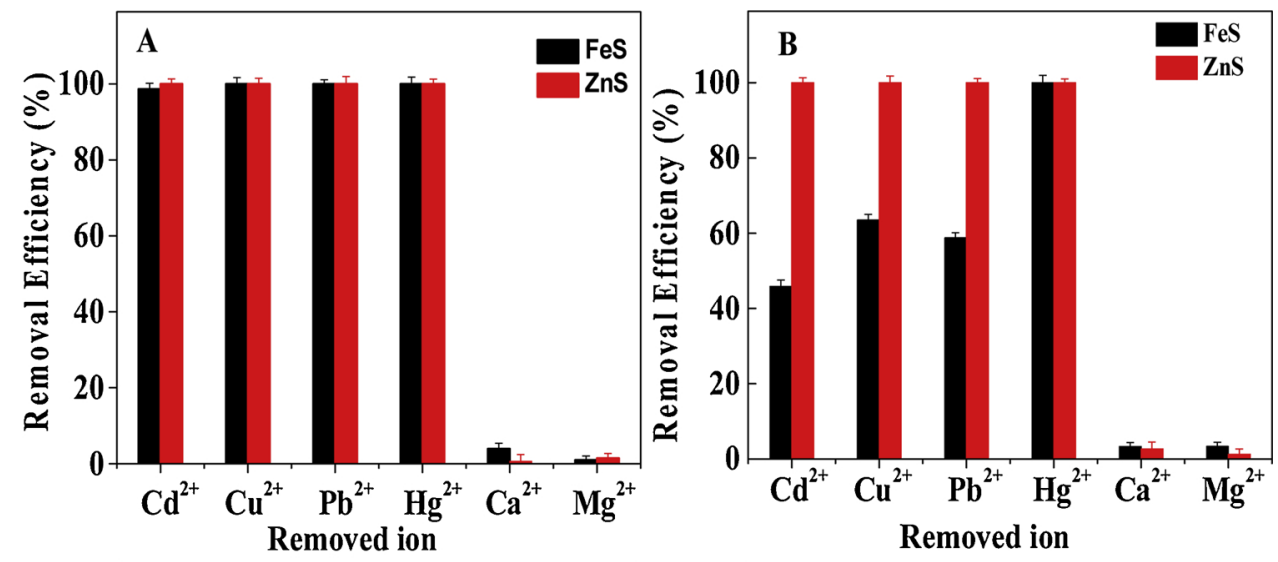

Fig. 2. Removal efficiency of various cations by $\mathrm{FeS}$ and $\mathrm{ZnS}$ in mixed competing cation solutions. Initial concentration of (A) $\mathrm{Cd}^{2+}$, $\mathrm{Cu}^{2+}, \mathrm{Pb}^{2+}, \mathrm{Hg}^{2+}$ is $1 \mathrm{ppm}, \mathrm{Ca}^{2+}, \mathrm{Mg}^{2+}$ is $60 \mathrm{ppm}$ and (B) $\mathrm{Cd}^{2+}, \mathrm{Cu}^{2+}, \mathrm{Pb}^{2+}, \mathrm{Hg}^{2+}$ is $10 \mathrm{ppm}, \mathrm{Ca}^{2+}, \mathrm{Mg}^{2+}$ is $600 \mathrm{ppm}$. Sample dosage is $1 \mathrm{~g} \mathrm{~L}^{-1}$. (C) Concentration of released $\mathrm{Cd}^{2+}$ from sulfide nanoparticles after reaction. (D) Capacity retention of sulfide nanoparticles for $\mathrm{Cd}^{2+}$ removal after exposure in air for 3 months.
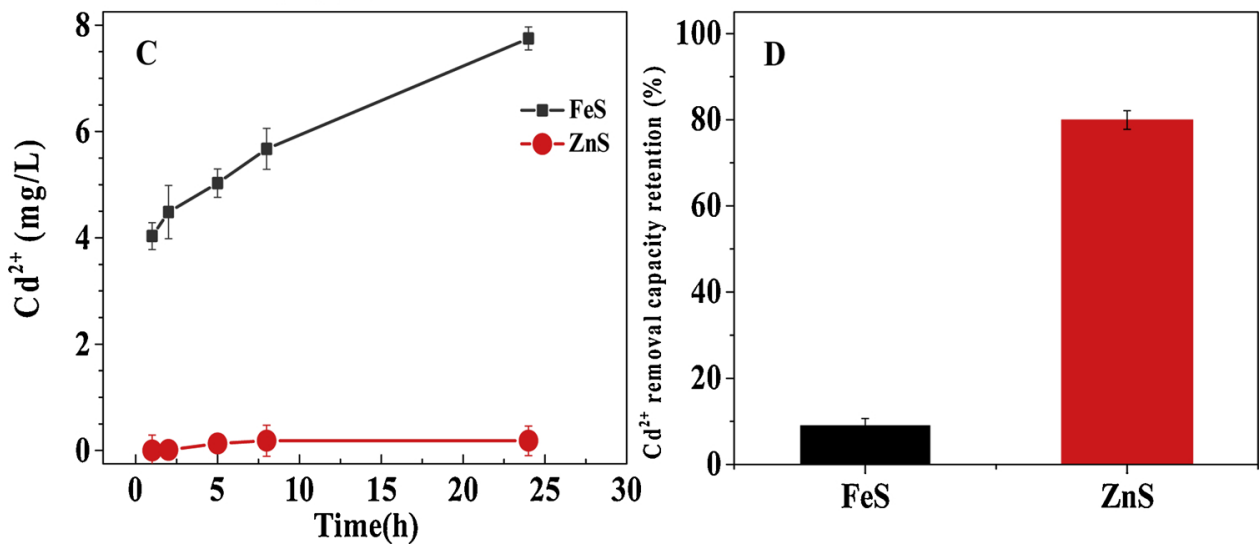

removal mechanism of cadmium with $\mathrm{ZnS}$.

Releases of metal ions and sulfate from sulfides during the adsorption processes are illustrated in Fig. 3. The release of $\mathrm{Zn}^{2+}$ from $\mathrm{ZnS}$ exhibited a gradually increasing trend while the concentration of $\mathrm{Zn}^{2+}$ reached a maximum $80 \mathrm{~h}$ later (Fig. 3B). The concentration of $\mathrm{SO}_{4}{ }^{2-}$ released from $\mathrm{ZnS}$ also remained stable, the amount of sulfate release was small and there was no general upward trend over time.

However, Fig. 3A shows increases of $\mathrm{Fe}^{2+}$ to a maximum concentration in the short term (the first hour) and then these values sharply decreased. With the re-release of $\mathrm{Cd}^{2+}$ in the latter processes of $\mathrm{FeS}$ treatment, it is obvious that the trend of $\mathrm{SO}_{4}{ }^{2-}$ release has the same tendency as that for $\mathrm{Cd}^{2+}$. By comparing the release of $\mathrm{SO}_{4}{ }^{2-}$ and the removal of $\mathrm{Cd}^{2+}$ during the reaction, it can be posited that FeS nanoparticles re-released $\mathrm{Cd}^{2+}$, after partial oxidation of CdS to form soluble $\mathrm{CdSO}_{4}$ (Pujalte et al., 2015; Gao et al., 2015), but the mechanism in this oxidation process needs further exploration.

It is clear that $\mathrm{Fe}^{2+}$ can be oxidized to $\mathrm{Fe}^{3+}$ in the presence of sufficient $\mathrm{O}_{2}$, by which process superoxide and peroxide can also be generated. In principle, $\mathrm{O}_{2}$ can be activated to form a variety of reactive oxygen species including the superoxide radical $\left(\cdot \mathrm{O}_{2}{ }^{-}\right)$, hydroxyl radicals $(\cdot \mathrm{OH})$ and singlet oxygen $\left({ }^{1} \mathrm{O}_{2}\right)$ (Badwey and Karnovsky, 1980). It is imperative to clarify which species is actually generated to provide the oxidative function. We conducted the tests by utilising several scavenger materials. Carotene, p-benzoquinone, tert-butanol and sodium fluoride can efficiently inhibit the generation of ${ }^{1} \mathrm{O}_{2}, \mathrm{O}_{2}{ }^{-}, \mathrm{OH}$ and $\mathrm{Fe}^{3+}$, respectively (Long et al., 2013; Wang et al., 2018b; Hotta et al., 2012). Fig. 3C shows the trends of $\mathrm{Cd}^{2+}$ concentration with $\mathrm{FeS}$ treatment in the presence of the various scavenger molecules. The addition of four different scavengers could all inhibit the re-release of $\mathrm{Cd}^{2+}$. Carotene exhibited the strongest inhibition of $\mathrm{Cd}^{2+}$ re-release at minimum added levels, suggesting that ${ }^{1} \mathrm{O}_{2}$ contributed the most to the oxidation of CdS to $\mathrm{CdSO}_{4} \cdot \mathrm{O}_{2}{ }^{-}, \cdot \mathrm{OH}$ and $\mathrm{Fe}^{3+}$ are also involved in the oxidation process.

\subsection{Proposed $\mathrm{Cd}^{2+}$ removal mechanisms}

The results of experimental batch tests indicated that the removal mechanisms towards $\mathrm{Cd}^{2+}$, of the two sulfides studied, are different. Fig. S3 illustrates the result from SEM-EDS analysis of samples, where significant increases in elemental $\mathrm{Cd}$ after the experiments can be clearly observed from the spectra (Fig. S3B and D), confirming that cadmium was successfully adsorbed onto the surface of the sulfide. The BET surface areas of FeS and $\mathrm{ZnS}$ were determined to be 6.94 and $9.51 \mathrm{~m}^{2} \mathrm{~g}^{-1}$, respectively. Compared with the huge difference in removal efficiencies of FeS and ZnS, the difference in BET surface area is not that significant, and there is little correlation, for both sulfides, between the capture ability of $\mathrm{Cd}^{2+}$ and BET surface area. It is thus reasonable to assume that $\mathrm{FeS}$ and $\mathrm{ZnS}$ nanoparticles may possess different removal mechanisms for $\mathrm{Cd}^{2+}$.

$\mathrm{XRD}$ analysis was conducted in order to identify the compositions of the sulfides before and after reaction with $\mathrm{Cd}^{2+}$. Before reaction with $\mathrm{Cd}^{2+}$, as shown in Fig. 4A, the representative diffraction peaks at the positions of $34.50^{\circ}, 49.59^{\circ}$ and $53.03^{\circ}$ matched well with the standard PDF card of FeS (JCPDS\#01-086-0389), confirming that FeS was successfully synthesized. In addition, the representative diffraction peaks of $\mathrm{FeOOH}$ and $\mathrm{Fe}_{2} \mathrm{O}_{3}$ were also identified in the product. These are common impurities in the fabrication process of FeS (Qiu et al., 2016). After reaction with $\mathrm{Cd}^{2+}$, the formation of CdS may be clearly observed.

The peaks of $28.91^{\circ}, 48.11^{\circ}, 57.11^{\circ}$ and $77.83^{\circ}$ (JCPDS\#01-0800020) in the XRD pattern (Fig. 4B-1) were identified in the new ZnS composites before $\mathrm{Cd}^{2+}$ adsorption. After $\mathrm{Cd}^{2+}$ adsorption, those peaks at $28.47^{\circ}, 47.28^{\circ}, 56.10^{\circ}$ and $76.37^{\circ}$ are very close to those for $\mathrm{Zn}_{0.9} \mathrm{Cd}_{0.1} \mathrm{~S}$ (JCPDS\#00-024-1137). The peak intensities significantly increase after reaction, which may be attributed to changes in particle morphology (Inoue and Hirasawa, 2013).

This suggests that the $\mathrm{Cd}$ might incorporate into the $\mathrm{ZnS}$ lattice by substitution for $\mathrm{Zn}$. Further Rietveld structure refinements of the 

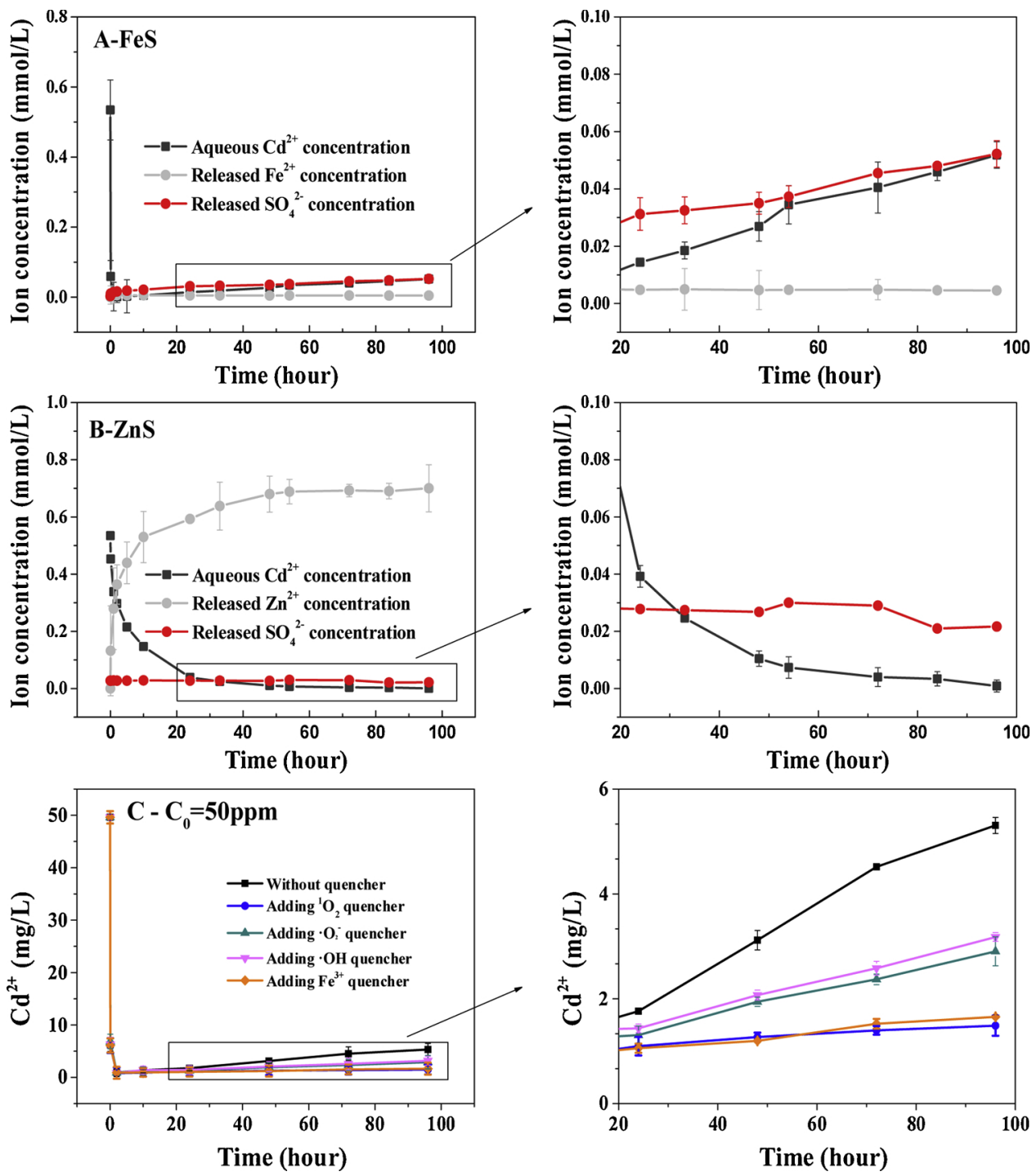

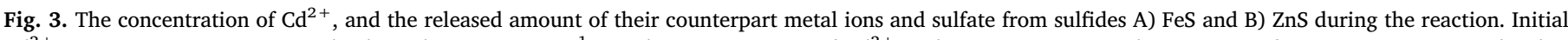

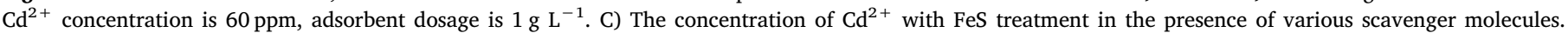

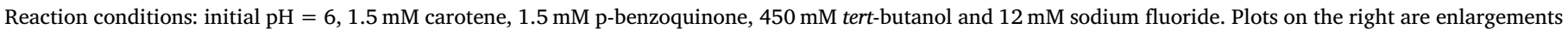
of boxed portions illustrated on the left.

original $\mathrm{ZnS}$ and $\mathrm{Cd}^{2+}$-loaded $\mathrm{ZnS}$ samples were conducted using the TOPAS software (Bruker Corp., USA), based on a ZnS standard structure (ICSD\#107150), and the results are presented in both Fig. 4B and Table S4. Analysis indicated that the lattice parameters for the $\mathrm{ZnS}$ sample were: $\mathrm{a}=3.8015(58) \AA$ and $\mathrm{c}=63.160(86) \AA$ respectively. The same parameters for the material after $\mathrm{Cd}^{2+}$ adsorption were 3.8125(93) $\AA$ and 63.42(14) $\AA$, respectively. This quantitatively confirms that $\mathrm{Cd}$ substituted for $\mathrm{Zn}$ in the adsorbent host and enlarged the lattice parameters, presumably due to the larger ionic radius of $\mathrm{Cd}^{2+}$ $(0.95 \AA)$ than that of $\mathrm{Zn}^{2+}(0.74 \AA)$ (Shannon, 1976).

From the XRD results, it can be preliminarily concluded that FeS removed $\mathrm{Cd}^{2+}$ by generation of $\mathrm{CdS}$, while $\mathrm{ZnS}$ formed the compound $\mathrm{Zn}_{\mathrm{x}} \mathrm{Cd}_{1-\mathrm{x}} \mathrm{S}(\mathrm{x}<1)$. However, because some of the peaks are adjacent, more characterization is required in order to draw more robust conclusions.

Further insights into the morphology and the crystal symmetry dynamics of the sulfide particles were gained from HR-TEM micrographs and from Raman spectroscopy. The HR-TEM images clearly present well-defined lattice fringes from the $\mathrm{FeS}$ and $\mathrm{ZnS}$ nanoparticles, indicating a high degree of crystallinity of the prepared materials (Fig. 5). The lattice fringe with the spacing of $2.43 \AA$ corresponds to the
(020) plane of CdS and could be observed on the HR-TEM images of FeS after reaction (Fig. 5A). $3.13 \AA$ is the lattice spacing of the crystalline plane (111) of $\mathrm{Zn}_{0.9} \mathrm{Cd}_{0.1} \mathrm{~S}$ (Fig. 5B).

Raman analysis is very sensitive to atomic bond vibration, through which very low levels of impurity may be identified (Kumar et al., 2018). Therefore, Raman spectroscopy is a useful tool to intuitively reflect whether the Cd removal process was a reaction between lattices or carried out by directly generating another substance such as CdS. It is interesting to note that the Raman spectral peak shapes, positions and intensities for FeS differed significantly before and after reaction. The characteristic bands of FeS at 308 and $672 \mathrm{~cm}^{-1}$ (Wang et al., 2018c) were observed in Raman spectra of FeS before reaction (Fig. 5C). The Raman band position at $305 \mathrm{~cm}^{-1}$ originates from CdS (Mahdi et al., 2014). In contrast to the Raman spectra of FeS, no new peaks representing $\mathrm{CdS}$ emerged after reacting $\mathrm{ZnS}$ with $\mathrm{Cd}^{2+}$, although changes in the position and intensity of peaks occurred (Fig. 5D). The characteristic band of $\mathrm{ZnS}$ is very close in position around $350 \mathrm{~cm}^{-1}$ (Sethi et al., 2010). The shifts in Raman patterns for ZnS may result from trace impurities or from defects in the lattice (Luo et al., 2007). As shown in Fig. 5D, the peak positions of $\mathrm{ZnS}$ are found to shift towards lower wavenumber $\left(345 \mathrm{~cm}^{-1}\right)$ and the peak intensites increased after 


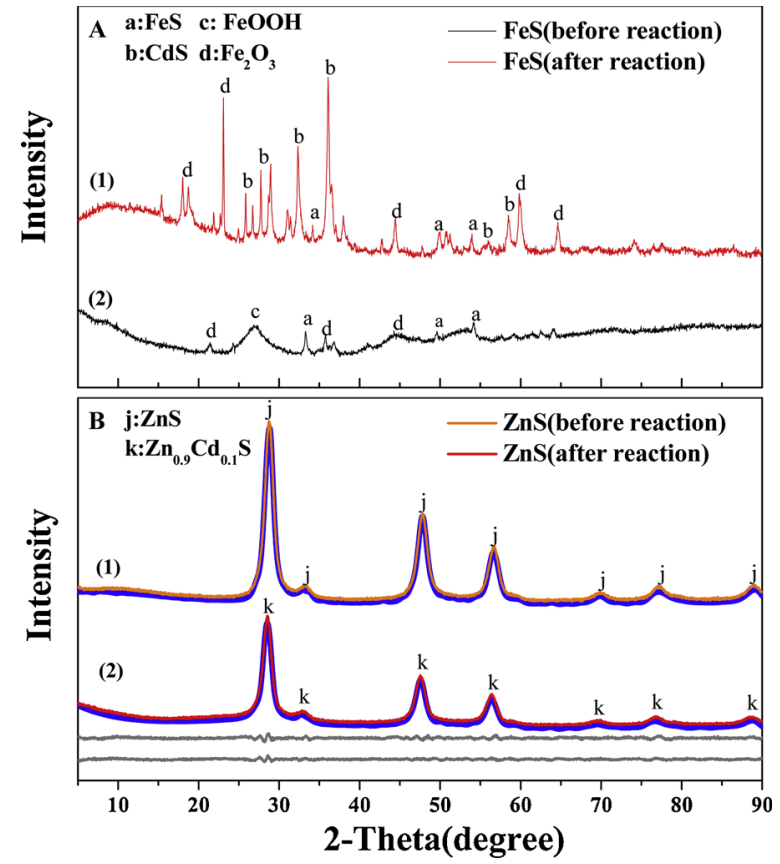

Fig. 4. Powder X-ray diffraction analysis of (A) FeS and (B) ZnS before and after reaction. In panel B the experimental data (orange and red lines) were overlaid with the best Rietveld structural refinement (blue lines), and the gray lines are difference patterns). (For interpretation of the references to colour in this figure legend, the reader is referred to the web version of this article).

the reaction with $\mathrm{Cd}^{2+}$. It has been previously reported (Sethi et al., 2010) that there is a significant wavenumber decrease, along with increases in intensity, in the vibrational modes observed with increasing amounts of Cd in ZnS alloy nanocrystals. Substitution of the lower atomic weight $\mathrm{Zn}$ atom by a $\mathrm{Cd}$ atom will change the peak intensity. It can be concluded that $\mathrm{Zn}_{\mathrm{x}} \mathrm{Cd}_{1-\mathrm{x}} \mathrm{S}(\mathrm{x}<1)$ is the main product after the removal of $\mathrm{Cd}^{2+}$ by $\mathrm{ZnS}$.

With reference to the results of XRD, HR-TEM and Raman spectral analyses, the proposed removal mechanisms of $\mathrm{Cd}^{2+}$ with $\mathrm{FeS}$ and $\mathrm{ZnS}$ nanoparticles can be summarised as follows (Fig. 6):

1) Chemical precipitation between $\mathrm{Cd}^{2+}$ and $\mathrm{H}_{2} \mathrm{~S}$ and formation of CdS
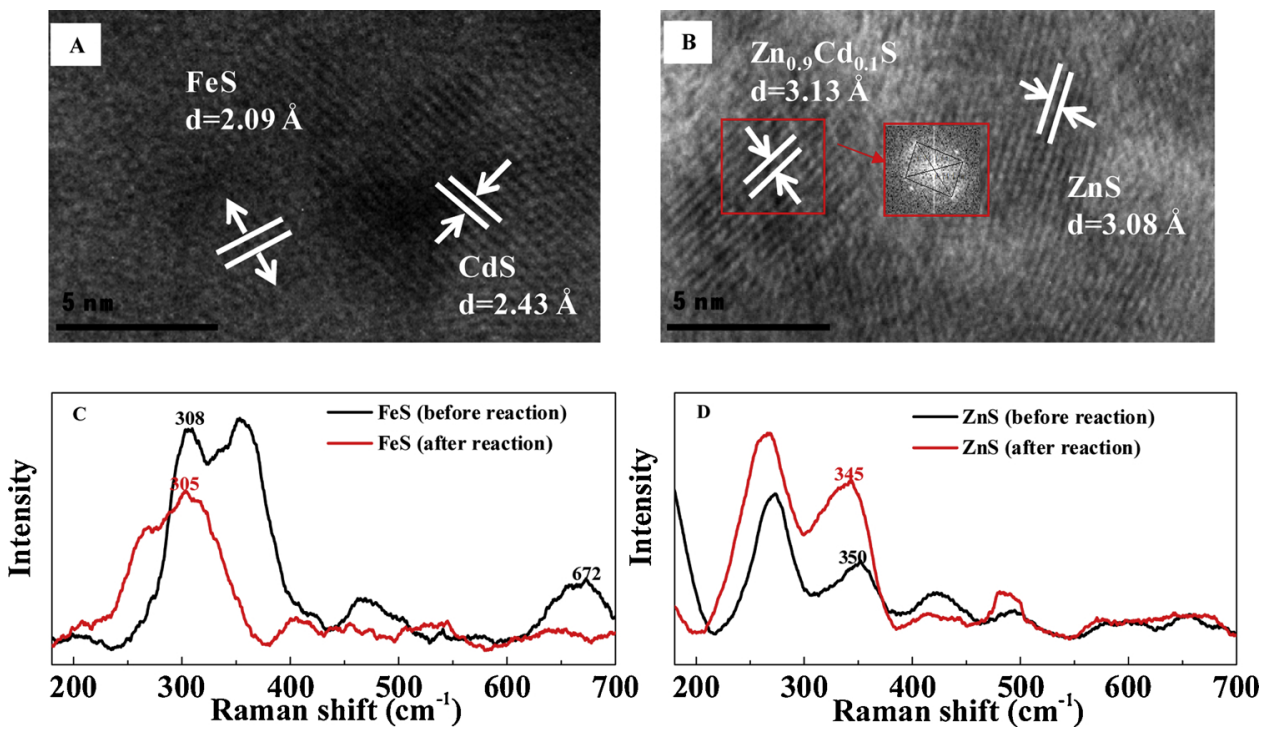

is the main mechanism of removal of $\mathrm{Cd}^{2+}$ by FeS, but that the CdS precipitated will then be partly oxidized to soluble $\mathrm{CdSO}_{4}$, leading to $\mathrm{Cd}^{2+}$ re-release.

2) The formation of $\mathrm{Zn}_{\mathrm{x}} \mathrm{Cd}_{1-\mathrm{x}} \mathrm{S}(\mathrm{x}<1)$ dominates the process for the removal of $\mathrm{Cd}^{2+}$ by $\mathrm{ZnS}$ nanoparticles. It has been reported that $\mathrm{Zn}_{\mathrm{x}} \mathrm{Cd}_{1-\mathrm{x}} \mathrm{S}(\mathrm{x}<1)$ has a $0.3 \mathrm{eV}$ higher binding energy (BE), compared with CdS, and that it possesses a solid solution structure, which could facilitate electron transport from $\mathrm{S}$ to $\mathrm{Zn}$ and $\mathrm{Cd}$, so that $\mathrm{Zn}_{\mathrm{x}} \mathrm{Cd}_{1-\mathrm{x}} \mathrm{S}(\mathrm{x}<1)$ is more stable than CdS (Chen et al., 2017). Therefore, ZnS exhibits greater $\mathrm{Cd}^{2+}$ removal capacity, higher chemical stability, a low re-release rate of the removed $\mathrm{Cd}^{2+}$, and is less prone to interference from many other heavy metal ions present in solution.

\section{Conclusion}

In this study, we proposed a new strategy for the highly efficient and irreversible removal of cadmium from water through the formation of solid solution $\mathrm{Zn}_{\mathrm{x}} \mathrm{Cd}_{1-\mathrm{x}} \mathrm{S}$. ZnS nanoparticles, exhibited a high $\mathrm{Cd}^{2+}$ sorption capacity of $401 \mathrm{mg} \mathrm{g}^{-1}$, which is higher than those previously reported for other materials. Moreover, this is achieved with negligible re-release of bound $\mathrm{Cd}^{2+}$. We have demonstrated that the extremely high capacity and strong affinity for $\mathrm{Cd}^{2+}$ could be ascribed to the formation of a solid solution, $\mathrm{Zn}_{\mathrm{x}} \mathrm{Cd}_{1-\mathrm{x}} \mathrm{S}(\mathrm{x}<1)$, which possesses better thermodynamic stability than CdS. For further applications, in addition to the previously-mentioned combination with PRB and fixed bed adsorption units, ZnS might be actively combined with other, relatively mature, materials such as biochar, magnetic oxides, etc., in order to synthesize more stable, dispersible, efficient or recyclable materials. This work opens possible new routes to the highly efficient and irreversible removal of heavy metals through the formation of solid solutions. We anticipate that our efforts will benefit future research in the remediation of contaminated environments.

\section{Author contributions}

The manuscript was written through contributions from all authors. All authors have given approval to the final version of the manuscript.

\section{Declaration of Competing Interest}

None.

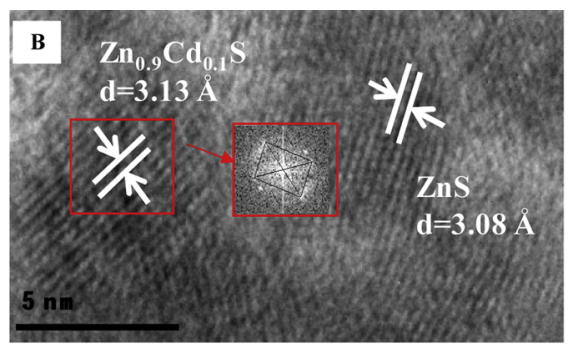

an spectra of (C) FeS and (D) ZnS before and after reaction with $\mathrm{Cd}^{2+}$. 


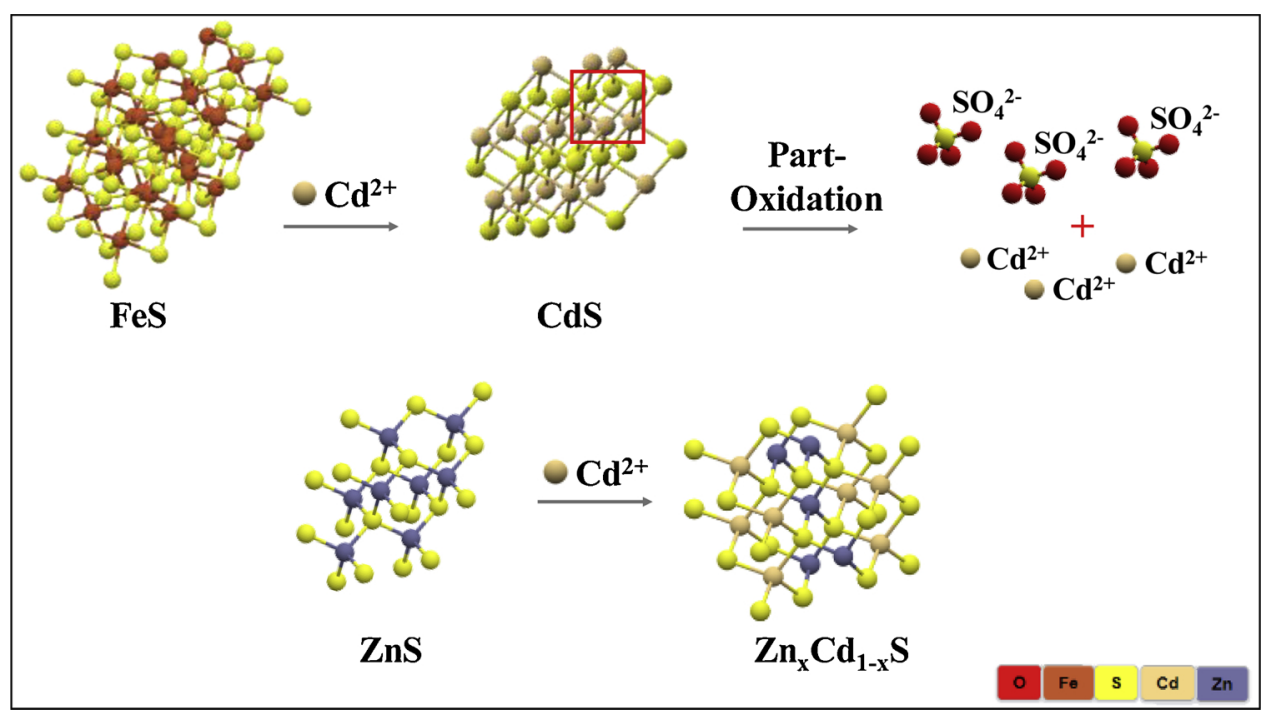

Fig. 6. Schematic representation for the proposed removal mechanisms of $\mathrm{Cd}^{2+}$ with FeS and $\mathrm{ZnS}$ nanoparticles.

\section{Acknowledgements}

This work was supported by the National Key R\&D Program of China (2017YFA0207204 and 2018YFD0800305), the National Natural Science Foundation of China (Grant No. 21806175 and 41771267) and Medical Technologies and Advanced Materials Strategic Theme at Nottingham Trent University.

\section{Appendix A. Supplementary data}

Supplementary material related to this article can be found, in the online version, at doi:https://doi.org/10.1016/j.jhazmat.2019.121461.

\section{References}

Abu-Danso, E., Peräniemi, S., Leiviskä, T., Bhatnagar, A., 2018. Synthesis of S-ligand tethered cellulose nanofibers for efficient removal of $\mathrm{Pb}(\mathrm{II})$ and $\mathrm{Cd}(\mathrm{II})$ ions from synthetic and industrial wastewater. Environ. Pollut. 242, 1988-1997.

Addala, A., Belattar, N., 2017. Adsorption of Cd and Pb metal ions onto chelating resin and their application in removal of lead from battery factory wastewaters. Indian J. Chem. Technol. 24, 601-607.

Adeleye, A.S., Conway, J.R., Garner, K., Huang, Y., Su, Y., Keller, A.A., 2016. Engineered nanomaterials for water treatment and remediation: costs, benefits, and applicability. Chem. Eng. J. 286, 640-662.

Badwey, J.A., Karnovsky, M.L., 1980. Active oxygen species and the functions of phagocytic leukocytes. Annu. Rev. Biochem. 49, 695-726.

Bailey, A.S., Batista, P.J., Gold, R.S., Chen, Y.G., de Rooij, D.G., Chang, H.Y., Fuller, M.T., 2017. The conserved RNA helicase YTHDC2 regulates the transition from proliferation to differentiation in the germline. Elife 6.

Chen, J., Chen, J., Li, Y., 2017. Hollow ZnCdS dodecahedral cages for highly efficient visible-light-driven hydrogen generation. J. Mater. Chem. A 5, 24116-24125.

Clemens, S., Aarts, M.G.M., Thomine, S., Verbruggen, N., 2013. Plant science: the key to preventing slow cadmium poisoning. Trends Plant Sci. 18, 92-99.

Fang, L., Li, L., Qu, Z., Xu, H., Xu, J., Yan, N., 2018. A novel method for the sequential removal and separation of multiple heavy metals from wastewater. J. Hazard. Mater. 342, 617-624.

Fu, F., Dionysiou, D.D., Liu, H., 2014. The use of zero-valent iron for groundwater remediation and wastewater treatment: a review. J. Hazard. Mater. 267, 194-205.

Gao, T.Y., Shi, Y., Liu, F., Zhang, Y.S., Feng, X.H., Tan, W.F., Qiu, G.H., 2015. Oxidation process of dissolvable sulfide by synthesized todorokite in aqueous systems. J. Hazard. Mater. 290, 106-116.

Gao, Y., Ren, X.M., Wu, J.C., Hayat, T., Alsaedi, A., Cheng, C., Chen, C.L., 2018. Graphene oxide interactions with co-existing heavy metal cations: adsorption, colloidal properties and joint toxicity. Environ.-Sci. Nano 5, 362-371.

Gong, Y., Tang, J., Zhao, D., 2016. Application of iron sulfide particles for groundwater and soil remediation: a review. Water Res. 89, 309-320.

Hotta, H., Kogure, Y., Tsunoda, K.-i., 2012. Determination of divalent trace metals in a soil sample using electrospray ionization mass spectrometry. Anal. Methods 4 1160-1162.

Inoue, M., Hirasawa, I., 2013. The relationship between crystal morphology and XRD peak intensity on CaSO4. 2H2O. J. Cryst. Growth 380, 169-175.

Kim, E.J., Kim, J.H., Azad, A.M., Chang, Y.S., 2011. Facile synthesis and characterization of Fe/FeS nanoparticles for environmental applications. ACS Appl. Mater. Interfaces 3, 1457-1462.

Kong, Q., Wei, C., Preis, S., Hu, Y., Wang, F., 2018. Facile preparation of nitrogen and sulfur co-doped graphene-based aerogel for simultaneous removal of $\mathrm{Cd} 2+$ and organic dyes. Environ. Sci. Pollut. Res. 25, 21164-21175.

Kumar, S., Supriya, S., Pandey, R., Pradhan, L.K., Singh, R.K., Kar, M., 2018. Effect of lattice strain on structural and magnetic properties of Ca substituted barium hexaferrite. J. Magn. Magn. Mater. 458, 30-38.

Lennartson, A., 2014. Zinc of unsuspected worth. Nat. Chem. 6, 166.

Long, R., Mao, K., Ye, X., Yan, W., Huang, Y., Wang, J., Fu, Y., Wang, X., Wu, X., Xie, Y., 2013. Surface facet of palladium nanocrystals: a key parameter to the activation of molecular oxygen for organic catalysis and cancer treatment. J. Am. Chem. Soc. 135, 3200-3207.

Luo, Y.-R., 2007. Comprehensive Handbook of Chemical Bond Energies. CRC press.

Luo, Y.Y., Duan, G.T., Li, G.H., 2007. Resonant Raman scattering and surface phonon modes of hollow ZnS microspheres. Appl. Phys. Lett. 90, 3.

Lv, D., Zhou, X.X., Zhou, J.S., Liu, Y.L., Li, Y.Z., Yang, K.L., Lou, Z.M., Baig, S.A., Wu, D.L., Xu, X.H., 2018. Design and characterization of sulfide-modified nanoscale zerovalent iron for cadmium(II) removal from aqueous solutions. Appl. Surf. Sci. 442, 114-123.

Ma, L.J., Wang, Q., Islam, S.M., Liu, Y.C., Ma, S.L., Kanatzidis, M.G., 2016a. Highly selective and efficient removal of heavy metals by layered double hydroxide intercalated with the MoS42- ion. J. Am. Chem. Soc. 138, 2858-2866.

Ma, L., Wang, Q., Islam, S.M., Liu, Y., Ma, S., Kanatzidis, M.G., 2016b. Highly selective and efficient removal of heavy metals by layered double hydroxide intercalated with the MoS42- ion. J. Am. Chem. Soc. 138, 2858-2866.

Mahdi, M., Hassan, J., Kasim, S., Ng, S., Hassan, Z., 2014. Optical properties of CdS micro/nanocrystalline structures prepared via a thermal evaporation method. Mater. Sci. Semicond. Process. 26, 87-92.

Mansurov, Y.N., Miklin, Y.A., Miklin, N.A., Nikol'skii, A.V., 2018. Methods and equipment for breaking down gold-containing concentrates from lean ores and mining industry waste. Metallurgist 62, 169-175.

Martin-Gonzalez, A., Diaz, S., Borniquel, S., Gallego, A., Gutierrez, J.C., 2006. Cytotoxicity and bioaccumulation of heavy metals by ciliated protozoa isolated from urban wastewater treatment plants. Res. Microbiol. 157, 108-118.

Pandey, L.K., Park, J., Son, D.H., Kim, W., Islam, M.S., Choi, S., Lee, H., Han, T., 2019. Assessment of metal contamination in water and sediments from major rivers in South Korea from 2008 to 2015. Sci. Total Environ. 651, 323-333.

Pirveysian, M., Ghiaci, M., 2018. Synthesis and characterization of sulfur functionalized graphene oxide nanosheets as efficient sorbent for removal of $\mathrm{Pb} 2+, \mathrm{Cd} 2+, \mathrm{Ni} 2+$ and $\mathrm{Zn} 2+$ ions from aqueous solution: a combined thermodynamic and kinetic studies. Appl. Surf. Sci. 428, 98-109.

Pujalte, I., Passagne, I., Daculsi, R., de Portal, C., Ohayon-Courtes, C., L’Azou, B., 2015. Cytotoxic effects and cellular oxidative mechanisms of metallic nanoparticles on renal tubular cells: impact of particle solubility. Toxicol. Res. 4, 409-422.

Qiu, G., Luo, Y., Chen, C., Lv, Q., Tan, W., Liu, F., Liu, C., 2016. Influence factors for the oxidation of pyrite by oxygen and birnessite in aqueous systems. J. Environ. Sci. 45, 164-176.

Qu, C., Shi, W., Guo, J., Fang, B., Wang, S., Giesy, J.P., Holm, P.E., 2016. China's soil pollution control: choices and challenges. Environ. Sci. Technol. 50, 13181-13183.

Qu, J., Meng, X., Jiang, X., You, H., Wang, P., Ye, X., 2018. Enhanced removal of Cd(II) from water using sulfur-functionalized rice husk: characterization, adsorptive performance and mechanism exploration. J. Clean. Prod. 183, 880-886.

Sahoo, A.K., Srivastava, S.K., Raul, P.K., Gupta, A.K., Shrivastava, R., 2014. Graphene nanocomposites of CdS and ZnS in effective water purification. J. Nanoparticle Res. 16, 2473.

Sethi, R., Sharma, P.K., Pandey, A., Kumar, L., 2010. Raman studies on Ag-ion doped CdZnS luminescent alloy quantum dots. Chem. Phys. Lett. 495, 63-68. 
Shannon, R.D., 1976. Revised effective ionic radii and systematic studies of interatomic distances in halides and chalcogenides. Acta Crystallogr. A 32, 751-767.

Sitko, R., Janik, P., Zawisza, B., Talik, E., Margui, E., Queralt, I., 2015. Green approach for ultratrace determination of divalent metal ions and arsenic species using total-reflection X-ray fluorescence spectrometry and mercapto-modified graphene oxide nanosheets as a novel adsorbent. Anal. Chem. 87, 3535-3542.

Su, J., Bi, L., Wang, C., Lyu, T., Pan, G., 2019. Enhancement of cadmium removal by oxygen-doped carbon nitride with molybdenum and sulphur hybridization. J. Colloid Interface Sci. 556, 606-615.

Su, Y., Adeleye, A.S., Keller, A.A., Huang, Y., Dai, C., Zhou, X., Zhang, Y., 2015. Magnetic sulfide-modified nanoscale zerovalent iron (S-nZVI) for dissolved metal ion removal. Water Res. 74, 47-57.

Tang, N., Niu, C.-G., Li, X.-T., Liang, C., Guo, H., Lin, L.-S., Zheng, C.-W., Zeng, G.-M., 2018. Efficient removal of $\mathrm{Cd} 2+$ and $\mathrm{Pb} 2+$ from aqueous solution with amino- and thiol-functionalized activated carbon: isotherm and kinetics modeling. Sci. Total Environ. 635, 1331-1344.

Wang, O., Wang, L., Li, Z.H., Xu, Q.L., Lin, Q.L., Wang, H.Z., Du, Z.L., Shen, H.B., Li, L.S., 2018a. High-efficiency, deep blue ZnCdS/CdxZn1-xS/ZnS quantum-dot-light-emitting devices with an EQE exceeding 18\%. Nanoscale 10, 5650-5657.

Wang, W., Zhu, Q., Qin, F., Dai, Q., Wang, X., 2018b. Fe doped CeO2 nanosheets as Fenton-like heterogeneous catalysts for degradation of salicylic acid. Chem. Eng. J. 333, 226-239.

Wang, Y., Wu, X., Wang, S., Xiao, F., Zhang, D., Yao, S., Jia, Y., 2018c. The adsorption behavior of thioarsenite on magnetite and ferrous sulfide. Chem. Geol. 492, 1-11.

Water, S., Organization, W.H., 2006. Guidelines for Drinking-Water Quality [Electronic Resource]: Incorporating First Addendum Vol. 1 Recommendations.

Watson, J., Ellwood, D., Deng, Q., Mikhalovsky, S., Hayter, C., Evans, J., 1995. Heavy metal adsorption on bacterially produced FeS. Miner. Eng. 8, 1097-1108.

Wu, J., Wang, X.B., Zeng, R.J., 2017. Reactivity enhancement of iron sulfide nanoparticles stabilized by sodium alginate: taking $\mathrm{Cr}$ (VI) removal as an example. J. Hazard. Mater. 333, 275-284.

Xiong, Z., He, F., Zhao, D., Barnett, M.O., 2009. Immobilization of mercury in sediment using stabilized iron sulfide nanoparticles. Water Res. 43, 5171-5179.

Zeuthen, C.M., Thorup, P.S., Roth, N., Iversen, B.B., 2019. Reconciling crystallographic and physical property measurements on thermoelectric lead sulfide. J. Am. Chem. Soc. $141,8146-8157$.

Zhang, X.M., Sarma, D., Wu, Y.Q., Wang, L., Ning, Z.X., Zhang, F.Q., Kanatzidis, M.G., 2016. Open-framework oxysulfide based on the supertetrahedral In4Sn16010S34 (12-) cluster and efficient sequestration of heavy metals. J. Am. Chem. Soc. 138, 5543-5546.

Zhang, H., Peng, L., Chen, A., Shang, C., Lei, M., He, K., Luo, S., Shao, J., Zeng, Q., 2019a. Chitosan-stabilized FeS magnetic composites for chromium removal: characterization, performance, mechanism, and stability. Carbohydr. Polym. 214, 276-285.

Zhang, X., Jia, F.F., Yang, B.Q., Song, S.X., 2017a. Oxidation of molybdenum disulfide sheet in water under in situ atomic force microscopy observation. J. Phys. Chem. C 121, 9938-9943.

Zhang, L., Jiang, D., Irfan, R.M., Tang, S., Chen, X., Du, P., 2019b. Highly efficient and selective photocatalytic dehydrogenation of benzyl alcohol for simultaneous hydrogen and benzaldehyde production over Ni-decorated Zn0.5Cd0.5S solid solution. J. Energy Chem. 30, 71-77.

Zhang, M.J., Huang, F., Wang, G.Y., Liu, X.Y., Wen, J.K., Zhang, X.S., Huang, Y.S., Xia, Y., 2017b. Geographic distribution of cadmium and its interaction with the microbia community in the Longjiang River: risk evaluation after a shocking pollution accident. Sci. Rep. 7, 12. 